\title{
EL AMOR COMO MODO PRIMORDIAL DE LA EXISTENCIA
}

\author{
Love as a Fundamental Way of Being
}

\author{
Sergio Molina Pérezi
}

\section{Resumen}

El hombre siempre está en relación, no puede no estarlo. Su mera existencia implica la relación con Dios, consigo mismo, con los demás y con el cosmos. Si bien la modernidad invita al individualismo, también existe la posibilidad de fomentar un ser más abierto a relacionarse conscientemente para reconocer todo lo que lo rodea y entenderlo como bueno para sí mismo. El presente artículo problematiza el concepto de amor como modo primordial de la existencia humana a partir de un diálogo con distintos autores de la tradición filosófica y teológica, mediante una metodología hermenéutica y en el marco del diálogo entre la filosofía clásica, la teología católica y el personalismo filosófico, integrados por una cosmovisión cristiana en la que el amor es uno de los conceptos fundamentales. Como punto de partida y, a manera de introducción, se ofrece al lector un marco del concepto de amor y la justificación de la noción de amor como modo primordial. Posteriormente, se dedica un apartado a distintas concepciones del amor en la historia del pensamiento y se explica la importancia de la razón como facultad humana en la experiencia del amor contra visiones irracionalistas muy propias de la posmodernidad. En lo sucesivo, se sustenta la existencia del modo amor en la relación del hombre consigo mismo y en el marco de la alteridad, con base, principalmente, en la propuesta personalista. Por último, se define el amor como modo de relación con el cosmos, considerando que amar y cuidar el mundo que se habita es una de las características del hombre que vive el amor como modo primordial de la existencia.

Palabras clave: Amor; Hombre; Relación; Modo Primordial; Dios; Modernidad; Ser; Razón; Personalismo; Cosmos.

1 Estancia Posdoctoral por la Universidad Autónoma de Madrid, España. Doctor en Filosofía por la Universidad Pontificia Bolivariana, Colombia. Correo electrónico: smolipe@gmail.com 


\section{Abstract}

Human beings are always in a relationship, they cannot avoid it. Just their existence involves a relationship with God, with themselves, with the others and with the cosmos. Though Modernity invites to individualism, there is also the possibility to promote human beings that are more open to consciously interact with others, to recognize everything that is around them and see it as a good to themselves. The article addresses the concept of love as a fundamental way of being human based on several authors of the philosophical and theological traditions, and following a hermeneutic method framed within the conversation of classical philosophy, catholic theology and philosophical personalism, which are brought together by a Christian worldview in which love is a fundamental concept. As a starting point and as a form of introduction, the article presents a framework of the concept of love and a reason for love as fundamental way of being. It then presents several ideas of love throughout the history of thought and explains why reason is a key human faculty for the experience of love, contrary to some views of postmodernism. Afterwards, it suggests love as mode of the relationship of human beings with themselves within the frame of alterity, based particularly on personalism. Finally, it establishes love as a mode of the relationship with the cosmos, considering that loving and taking care of the world is one of the features of the human beings who live love as a fundamental way of being.

Keywords: Love; Human Beings; Relationship; God; Modernity; Being; Reason; Personalism; Cosmos.

\section{Introducción}

Cada vez que un hombre obtiene un logro, justifica y reconoce su esfuerzo, disciplina y empeño. Lo mismo ocurre con la humanidad y los proyectos colectivos en los que los dirigentes confieren el éxito y obtención de los buenos resultados a la metodología, la ciencia, la técnica y la coordinación sistemática de los recursos. Casi todos se entretienen y distraen dándole mérito a los medios técnicos que les permitieron finiquitar lo que algún día se propusieron. Se ofrece aquí un pronunciamiento oportuno para poner las cosas en su lugar y llamarlas por su nombre. Asumir pautas de ordenamiento en todo proceso que emprenda el hombre es apenas necesario para la consecución de los fines respectivos. Sin embargo, se olvidó el sano propósito de las personas, el ánimo de hacer sus oficios con el objeto de servir más y mejor al semejante, y la invitación a la ética como principio recto de sus acciones. Según el estudio de López:

En México, la promoción de la participación comunitaria es urgente ya que, como lo afirma la Encuesta Nacional sobre Cultura Política y Prácticas Ciudadanas (ENCUP), el 44\% de los ciudadanos mexicanos entrevistados consideran que trabajar por una causa común es difícil o muy difícil, pero es una acción que consideran de utilidad y de uso frecuente para solucionar problemas que los aquejan. Los ciudadanos mexicanos manifiestan también en tal estudio poca confianza en instituciones como sindicatos, congreso, partidos políticos y el mando policial, pero aún confían en otras instituciones que promueven la acción comunitaria como la Iglesia, la escuela y el ejército. El 62\% de los encuestados afirmó tener poco interés en los problemas de su comunidad; y el $71 \%$ dijo que no asiste a reuniones para resolver los problemas del barrio, la colonia o la comunidad. En contraste con lo anterior; tres cuartas partes de los ciudadanos reportados en la encuesta manifiestan orgullo de ser mexicanos (2020, p. 84). 
Aunque el amor es fundamento de la vida humana y causa final de la existencia -como indican el texto bíblico (Jn. 13, 34; 1Jn. 4, 8) y la tradición (Catecismo de la Iglesia Católica No. 1)-, el pensamiento moderno y los afanes consumistas propios de la mentalidad capitalista hacen que el hombre olvide servir al otro por solo procurar la figuración, la fama y el rédito económico. Occidente se ha equivocado llamando productividad a lo que, en resumen, es un acto amoroso. No cabe duda que el amor es fundamental como ingrediente de la actividad humana, no cualquier insumo; es garante y facilitador de las metas del hombre. Se ha enseñado la técnica y se ha aplaudido la destreza sin que se fomente el "modo amoroso" como principio rector del servicio y de la relación con el otro.

Así las cosas, se le ha conferido excesivo valor a la metodología, a la estructura organizacional y a la enunciación de planes, programas y proyectos que solo se fundamentan en la competitividad con altos costos humanos (Bauman, 2005). Hasta el hombre, en su intimidad y bajo el silencio de su casa, olvidó reflexionar en cuanto al valor y la belleza de sus actos para la consecución del bien personal y comunitario, esencia de la ética y la política (Gómez, Castellanos \& Amaya, 2020). Todo es afán, nada se saborea. El siglo XXI sigue empeñado en que todos le ganen a todos, en que los hombres sean autómatas y no seres racionales (Figari, 2004). Olvidan lo esencial, olvidan los fines reales de la acción, olvidan lo vital y, sobre todo, olvidan el amor como modo primordial, tema del presente artículo.

Así pues, esta introducción ha hecho un recuento del concepto de amor y ha abordado la necesidad de la razón en el amor contra perspectivas románticas o emotivistas como pasos obligados para desarrollar las razones suficientes para hablar del amor como modo primordial. A continuación, se pasa a la parte central de este estudio. En el segundo apartado, dedicado a las concepciones del amor y el lugar de la razón en la vivencia del amor, se reivindica la presencia de la reflexión racional en la experiencia del amor, superando perspectivas emotivistas. Posteriormente, se explica el modo amor en la relación del hombre consigo mismo y con los demás, recurriendo, de manera especial, a la visión que ofrece la corriente filosófica personalista. En cuarto lugar, se desarrolla el amor como modo de relación con el cosmos, habida cuenta de que amar la casa que habita es actitud propia del hombre que ama a los semejantes y a todo aquello que le resulta provechoso con vistas a su subsistencia.

\section{Las concepciones del amor y el lugar de la razón en la vivencia del amor}

El amor es uno de los temas más vastos y desafiantes en la historia de la filosofía. El amor tiene muchas formas que se han recogido en las lenguas clásicas con conceptos como éros, entendido como el amor de atracción, el deseo de la belleza, trascendente a un contenido meramente sensual o sexual como usualmente se lo ha interpretado (Gómez, 2019); filía, amor de "amistad, benevolencia, afecto" (Pabón, 2009). A diferencia del éros, entendido como amor natural, aparece el agápe. entendido como amor personal. En el primero hay inclinación natural hacia los actos para los cuales se está capacitado. Se refiere más al deseo natural del hombre por la belleza que quiere para sí, mientras que en el segundo hay entrega del propio ser por liberalidad. Por consiguiente, dado que la naturaleza y la persona son dos dimensiones metafísicas de la realidad, el éros, como amor natural y el agápe, como amor personal, son también algo metafísico y, por consiguiente, la virtud de la charitas, traducción latina de agápe y virtud moral que en castellano se traduce como caridad, mueve al ser humano porque este se encuentra previamente instalado en la situación metafísica del amor (Zubiri, 1980). 
Sin embargo, más allá de la aproximación erudita al amor sobre la que ya se ha escrito bastante a lo largo de la historia humana, es necesario aclarar que cada quien según su formación -o, en el peor de los casos, su amaño-, concibe el amor de una determinada forma. La concepción del amor y los elementos que lo constituyen dependen de factores tan relevantes como la cultura y la religión. El amor no existe sino hasta cuando se materializa. El acto amoroso es advertido por los sentidos de la persona desde los primeros instantes de su vida materializado en la caricia, en la sonrisa benevolente, en la palabra que alienta y consuela, en el aroma de lo que representa cercanía y confianza (Seifert, 2018).

Sin embargo, suponiendo que los hombres carecieran de esta excelsa vivencia del amor en la cuna -lo cual parece más realidad que ficción en los días que corren-, la reflexión en torno a este tópico quedaría en manos de lo que la sociedad y la academia bien o mal puedan aportar o a la iniciativa de quien quiera autónomamente inquietarse o admirarse por el amor como modo primordial de ser y de existir, y por los propios modos del amor, entendiendo esta expresión en su sentido metafísico, muy ligada a los trascendentales del ente bonum y pulchrum.

Los modos reales son afecciones entitativas que no poseen consistencia propia independiente de otra entidad. Su realidad ontológica es, pues, más débil que la de los accidentes. Pero son importantes, porque permiten establecer — mediante la distinción llamada modal — distinciones entre una entidad y algunas de sus modificaciones reales. Los modos reales pueden ser de varias clases: modos sustanciales, modos accidentales, modos de inherencia, etc. Duns Escoto habló de 'modos intrínsecos', entendiendo por ellos ciertas determinaciones intrínsecas de la esencia; el modo intrínseco expresa el modo como un sujeto es lo que es. Así, 'audible' en 'sonido audible' no designa un modo intrínseco del sonido, el cual puede ser audible o no serlo. Pero 'fuerte' en 'sonido fuerte' designa un modo intrínseco del sonido, pues pertenece intrínsecamente al sonido la posibilidad de ser fuerte o no serlo (Ferrater, 2004, p. 437).

Con base en esta concepción metafísica y realista del amor y sus modos se afirma aquí la necesidad de conocer para distinguir y poder amar lo conocido. Invertir el orden también es posible, pues el amor y la razón conforman un ciclo en el que, muchas veces, es imposible discernir qué va primero: se ve al amado y se razona sobre él, se lo verifica, se contempla y se goza el amante en su belleza y, al gozarse, se lo aprecia, pues apreciar es amar (Cruz, 1999). El amor puede ser estímulo primero que lleva a la razón a "la confirmación de amor", que no es más que la reiteración de que el amado o lo amado está siendo provechoso para el amante. Sobre todo a partir del Romanticismo, ha existido una obligación implícita o, por lo menos, una fuerte tendencia a oponer amor y razón (Abrams, 1992). Así entonces, la primordialidad del amor como modo lleva implícita la unión entre el amor y la razón simultáneamente, con base en una antropología integral que no disocia lo intelectual y lo volitivo, lo noético y lo sentimental, lo contemplativo y lo afectivo (Yepes \& Aranguren, 2003).

En torno a la razón y el amor romántico, por ejemplo, inquietan los siguientes interrogantes: ¿El enamorado está siendo afectado por el sentimiento en la medida que no razona sobre su acontecimiento de amor? La desazón que da el riesgo de perder lo amado y la frenética lucha por retenerlo ¡es un acto irracional? O bien, ¿pudiera decirse que es una racionalidad a medias? Si le pierdo y me deja, padeceré su ausencia[...]Si se va de mi lado, soy incompleto[...] al no tenerle, seré infeliz son ideas que suelen pasar por la cabeza del amante, llenándolo de miedo ante posibles males futuros (Polaino, 2000). Infiere, pues, que la ausencia del otro o el desprecio del otro es sinónimo de desgracia o señal cierta de poco valor personal. 
Así también, la presencia del otro, y el reconocimiento que le hace, lo llevan a concluir que es afortunado, privilegiado sobre otros, premiado con el amor que viene desde afuera. En ambos casos hubo un proceso mental asociativo: me aman, soy feliz; me eligen, ergo, existo para alguien.

Una conclusión complaciente al ego no se debe entender como una conclusión verdadera o correcta, pues la razón debe orientar a la voluntad y esta a la sensibilidad. Por lo cual, es válido sugerir la conveniencia de que la razón formule preguntas como: ¿por qué quiero amarle?, ¿por qué y para qué quiero ser amado? El raciocinio completo debe incluir un final provechoso para el ser, en términos de su fomento individual, aunque no individualista. El amor vinculado al provecho moral y espiritual de los amantes es el amor verdaderamente constitutivo de lo bueno, lo que fecunda a la persona y promueve un buen modo de existir. Al respecto, resultan aclaradoras las ideas de Pieper sobre la presunta oposición entre éros y agápe que tomó fuerza, especialmente, a partir de la publicación del libro, en dos partes, Eros y Agape (1930 y 1936) del teólogo luterano de origen sueco Anders Nygren:

Parece que hay una diferencia clara entre que yo desee que la otra persona exista por mí, porque yo, por ejemplo, la necesito, y que se lo desee por ella misma, porque quisiera verla feliz y que llegara a la plenitud a que está destinada. Y si es por mí por lo que yo digo eso, ¿puede seguir diciéndose que amo a la otra persona?

Por lo que se refiere a las cosas, no hay problema para contestar. Naturalmente que "amamos" el vino por nosotros mismos. "Sería ridículo, dice Aristóteles, desear el bien al vino" (es decir, quererlo por él mismo); 'a lo sumo se desea que se conserve bueno para poder disfrutarlo'.

Santo Tomás de Aquino afirmó que en la capacidad de sentir la convenientia sensibilium, es decir, la calidad sensible y perceptible por sí misma, sin el grito de la pasión poseedora, hay algo específico del ser humano, pues el animal desea únicamente lo que le sirve posiblemente de alimento o para la unión carnal, mientras que el hombre, dominando sus apetitos, se hace capaz de disfrutar de la belleza puramente sensible como puede ser la del cuerpo humano. Pero de nuevo nos hemos situado en la relación entre personas. En todo caso queda suficientemente claro que no hay nada desordenado en que yo "ame" determinadas cosas por mí, o sea, para mí: “¡qué maravilla que exista eso... para mí!” (Pieper, 2017, pp. 333-334).

El raciocinio lleva a validar el amor dentro del ser, es un cedazo que califica si ese amor es provechoso o no. Espléndido es el amor que luego de la verificación racional aún prevalece, que, incluso, se vuelve más excelso por legitimarse como un auténtico sentimiento y no como un impulso, una imposición social o una mera consecuencia de la mala formación moral de la persona.

En las emociones se diluye la participación intelectual, siempre dependiendo de la intensidad y duración que éstas tengan. Los sentimientos se dejan más fácilmente atrapar y analizar por razonamientos noéticos. Es una síntesis de lo vivido, comprensión lógico-racional, distinción entre lo que en él ha sido accesorio y fundamental (Rojas, 2004, p. 71).

La necesidad de pensar el amor es imperiosa, aprender a amar verificando con la razón. Amar no es un acto ventajoso para servirse del otro, es un acto en el que uno suma con otro, de forma que ambos actúan amorosamente en una celebración que es provechosa para la comunidad, para aquellos que ven en este amor un testimonio que los edifica como personas (Hahn, 2001). 
Aristóteles y Platón definieron la educación como el proceso mediante el cual se hace que el niño guste de lo bueno, de lo adecuado a su naturaleza (Lewis, 2014). San Agustín, por su parte, definió la virtud como ordo amoris, esto es, orden en el amor (La Ciudad de Dios XV, 22). En síntesis, el lugar de la razón en la vivencia del amor consiste en ser la facultad mediante la cual se juzga la pasión amorosa, considerándosela buena si lo amado es conveniente al ser para su perfeccionamiento integral y si la forma de amor es la adecuada a la riqueza de lo amado. En ese sentido, es esencial distinguir la pasión del amor y el amor virtuoso, superando el romanticismo que afirma un amor en el que la razón no tiene ningún lugar. Es este uno de los principales desafíos de la posmodernidad, que debe ser enfrentado mediante una revitalización de la ética clásica y de la teología cristiana.

Así mismo, la euforia del enamoramiento ¿es un acto irracional? El embeleso romántico no admite preguntas como: ¿por qué le amas? o ¿es provechoso ese amor? Cualquier relación que admita cuestión y reflexión, y cualquier enamorado que no se resista a la pregunta - preferiblemente su propia pregunta- es un amante provechoso que, muy seguramente, propiciará una relación nutritiva al ser y estimulante para los testigos de ese amor, quienes lo celebrarán porque embellece el mundo y la vida (Pieper, 2006).

Otra pregunta cuya respuesta confirma la tesis del amor como modo primordial y constitutivo del hombre es aquella que un hombre de buena voluntad se formula continuamente a sí mismo: ¿cómo es mi actuar? El acto es reflejo del alma, quiérase o no, el ser actúa desde su buena o mala educación moral; lo que se hace es concordante con lo que se es. Ahora bien, lo que se es -y, así mismo, lo que se hace- podrá validarse como bueno o malo. Entendiendo que buena parte de lo constitutivo en la persona es fruto del testimonio y la instrucción de otro (bien o mal formado), puede concluirse, sin duda, que la persona del presente es copia mejorada o deformada del pasado (Hahn, 2009). Se hablaría aquí, entonces, del amor y sus modos, buenos o malos, con respecto a sí mismo y a los demás.

\section{El amor, modo de la relación consigo mismo y con los demás}

Para referirse al amor propio habrá que desafiar la afirmación, según la cual, amarse y cuidarse son placeres que fomentan el egoísmo y obran en favor del individualismo. Quizá sea una posibilidad en el megalómano autorreferencial que no trasciende hacia lo que significa amar en todas sus posibilidades (amarse, amar al otro, actuar con amor). Sin embargo, la tradición filosófica realista y el personalismo han mostrado que es posible una mirada amorosa hacia sí mismo sin perjuicio de la alteridad. En la literatura exhibida en los supermercados, la autoayuda aparece como posibilidad terapéutica que conecta al hombre con su yo aunque se fundamente en el éxito, la riqueza material o la fama. No importa si la excusa para hallarse se encuentra en un libro bajo el título de "Hágalo usted mismo"; ya, en principio, es bueno ese primer reconocimiento que gira la mirada a las calidades de quien lo lee. El personalismo invita a la donación y al gusto por crecer reconociendo al otro (Burgos, 2009). Posiblemente, sea ambicioso esperar que el lector desprevenido migre de su mezquino deseo de ser exitoso y llegue al buen puerto del bienestar colectivo. Le tomará tiempo, pero, en principio, ya es algo que esa reflexión sea motivada o catalizada.

Empezar por sí mismo no es egoísmo ni vanidad, es autocuidado. Quizá otros caminos de interacción social se enfoquen en entender y apreciar al otro, sin embargo, esa fórmula puede estar equivocada en el 
supuesto de que no solo es más fácil empezar por el conocimiento de sí mismo, sino más razonable. El amor propio es también primordial para sí mismo, pues el yo es lo más inmediato que tiene el hombre. Así mismo, la mejor narración de la vida es su propio testimonio, pues su conciencia vigila sus actos y su autonomía los aprueba. El retorno al yo y no al estímulo exterior permitirá formular las preguntas esenciales de una vida con valor: ¿quién soy? ¿por qué estoy aquí? ¿con quién estoy? y ¿para qué somos y estamos los seres humanos en el mundo? (López, 2013). La formulación básica y el raciocinio deberán primero estribar en este aspecto que, en apariencia, es tan elemental.

El amor aparece luego de la primera pregunta sobre el ser y el estar; venir del amor y reconocerlo como el sentimiento primordial permite conjeturar que este prevalece en todo hacer humano. Lo que se es, es dado, de ahí la importancia del aprecio propio y la valoración de lo que se es.

Desde la perspectiva genealógica de Foucault, el cuidado de sí se entiende como un conjunto de prácticas mediante las cuales un individuo establece cierta relación consigo mismo y en esta relación el individuo se constituye en sujeto de sus propias acciones (Garcés \& Giraldo, 2013, p. 188).

Foucault, en su etapa ética, pensaba que la vida se debería asumirse como una obra de arte, como un proceso creativo de transformación individual:

Se trata de hacer de la propia vida una obra de arte, de liberarse del pegajoso contagio que secretan unas estructuras sociales en las que rige la ley del sálvese quien pueda'. El sujeto ético es aquel que pretende hacerse a sí mismo. Aquel que busca forjarse un sentido cautivador a su existencia (Garcés \& Giraldo, 2013, p. 188).

Una vez se da el encuentro con lo propio puede darse un adecuado y acertado encuentro con lo ajeno. Por esto, cobra especial importancia que el hombre se examine en detalle y se conozca, valorando el misterio que resulta ser, incluso para sí mismo, pero esforzándose al máximo de su capacidad racional para comprender las dimensiones cognoscibles de su propia identidad (Esparza, 2013). Esa inquietud acerca de las causas de las cosas y, sobre todo, de lo que podría llamarse una etiología de si mismo, no es, propiamente, el cuidado propio, sino su condición sine qua non, su requisito indispensable. El hacer es posterior al ser y solo podrá saber qué acciones incluye su autocuidado aquel que sepa quién es y trabaje continuamente en su conocimiento personal (García, 2018).

Hay que insistir: cuidarse a sí mismo no equivale a egoísmo como una concepción puritana y rigorista de la vida humana podría sugerir. De hecho, quien se cuida se prepara para cuidar a los demás y para cuidar el mundo (Domingo, 2013). Al respecto, serán siempre célebres las exhortaciones de Sócrates al joven Alcibíades quien, ansioso por forjar una brillante carrera política, se había olvidado de la práctica personal de la virtud y del trabajo consigo mismo. Por tanto, el gran maestro de la juventud griega lo invita a considerar una situación hipotética detrás de la cual se esconde una gran lección moral:

Hazme caso a mí y a la máxima de Delfos 'conócete a ti mismo', ya que tus rivales son estos y no los que tú crees, rivales a los que no podríamos superar por otro medio que con la aplicación y el saber. Porque si tu careces de estas dos cosas, también te verás privado de llegar a ser famoso entre los griegos y los bárbaros, lo que, si no me equivoco, estás ansiando más que ninguna otra cosa en el mundo (Alcibiades 123e-124b). 
Desde el personalismo, esta formación de sí para la formación de otros y el amor a sí mismo como condición para el amor a otros podrían entenderse desde la categoría donación. Nadie se ama ni se sirve solamente a sí mismo y quien intenta vivir así se frustra en su realización como persona, ya que dicha realización depende, precisamente, de la donación. Sócrates sugiere el ocuparse de sí como un acto que apunta a cuidar al otro y a la ciudad. Este fundamento de la realización personal desplaza la mirada del hombre de sí mismo hacia su entorno y lo abre a una relación abierta con el cosmos y con los demás. Sobre este asunto en particular, Burgos afirma:

La centralidad de la interpersonalidad ya ha sido puesta de relieve, en particular, al tratar de la filosofía del diálogo. El hombre nace de una relación entre sus padres y, nada más nacer, establecer con ellos especialmente con la madre- un vínculo intensísimo que afectará decisivamente a su futuro. Asimismo, las relaciones amicales, la educación, la cultura, etc., influyen en la construcción de su identidad. Además, la relación interpersonal no es pasiva, no se limita a influjos que la persona recibe, sino que es el lugar antropológico para su autorrealización a través de la donación: 'el hombre, única criatura terrestre que Dios ha amado por sí misma, no puede encontrar su propia plenitud si no es en la entrega sincera de sí mismo a los demás'. La persona debe darse a través de la relación para construirse a sí mismo en un proceso paradójico que convierte la salida de sí en un enriquecimiento y fortalecimiento de la propia identidad (Burgos, 2012, p. 279).

El autocuidado como celebración ética es justificación suficiente para referir su necesidad, bien sea desde el conocimiento de sí o desde la autovaloración, ya que, como antes se dijo, solo se ama lo que se conoce. En Heidegger (2002) se hace referencia al autocuidado como un elemento originario y constitutivo, esencial. Esta concepción de la esencialidad del conocerse, acentúa la prioridad de considerar el amor como modo primordial en todos los actos humanos.

Cuidar de las cosas que atañen a la propia vida y al propio cuerpo no garantiza cuidar de sí mismo. Cuidar la salud ya está bien, pero Sócrates acentúa el cuidado del alma, la verdad y la razón como aspectos esenciales del hombre que deben fecundarse con determinación por sí mismo (Hadot, 2006). Edificarse y cultivarse es una autodeterminación cuya inclinación es inherente a la naturaleza humana. Es una necesidad que el ser humano busca satisfacer, pues, así como el amor a los demás, el amor propio puede exagerarse o ser deficiente, pero es inevitable y no optativo. ¿Quién decide no amarse? El autodesprecio supondría el suicidio, pues ¿qué motivaría vivir si no se está a gusto con la vida propia? -no obstante, el suicida ve la muerte como un bien para sí, algo que quiere conseguir, en lo que hay, todavía, un reducto de amor propio-. El conocimiento propio no es aceptación a la fuerza, no es menosprecio ni subestimación, es celebración de un fenómeno propio que es la vida de cada uno (Foucault, 2011).

La autodeterminación de valorarse debe ser una constante en la sociedad actual de modo que el hombre no interprete su valía como un acto egocéntrico y "autosuficiente" (Quiles \& Espada, 2010). La autosuficiencia renuncia al otro y todo amor se queda guardado, al menos no se postula al afuera, se gesta en el ser, pero sin relación con el exterior.

Entre el reconocimiento de sí mismo y de los demás no hay oposición, sino un continuum natural y dinámico (Gómez, 2013). Por otro lado, cabe aclarar que el estímulo que viene de la estima y el reconocimiento exteriores puede, peligrosamente, generar vanidad o vanagloria más que autovaloración. 
Este vicio, que Tomás de Aquino clasifica como uno de los opuestos a la virtud cardinal de la fortaleza, es definido por el Aquinate con las siguientes notas:

No es pecado querer que otros aprueben las obras buenas, porque se nos dice en Mt 5,16: Asi ha de lucir vuestra luz ante los hombres. Por tanto, el deseo de la gloria de suyo no es vicioso. Pero el deseo de una gloria vana implica vicio, porque toda apetencia de algo vano es vicioso, según el salmo 4,3: ¿Por qué amáis la vanidad y seguís la mentira? Ahora bien: la gloria puede ser vana en primer lugar por parte de la cosa de la cual se busca la gloria; por ejemplo, si uno busca la gloria en lo que no existe, o en lo que no es digno de gloria, por ser frágil y caduco. En segundo lugar, por parte de aquel de quien se espera la gloria, v.gr. del hombre, cuyo juicio no es cierto. En tercer lugar, por parte del que ambiciona la gloria, al no referir su deseo de gloria al fin debido, como es el honor de Dios y la salvación del prójimo (Suma de Teología II-II, q. 132, a. 1, resp.).

El mensaje que dice "te aprecio" es distinto al que sugiere que los atributos de la persona a quien se dirige el mensaje son supremos y únicos. El reconocimiento de otros puede significar que se va por buen camino en la vivencia del amor, un espejo que retorna la certeza de que los actos propios generan bien a los demás o son bien vistos. Sin embargo, el autocuidado no se reduce a eso; además de la afirmación gozosa del otro, debe haber una voz propia que, como fruto de la sindéresis como proceso intelectual de la razón práctica, confirme, con base en principios morales reales y sólidos, que la conducta propia es amorosa, es decir, que está signada por el amor como modo primordial.

\section{El hombre, creado por amor y su relación amorosa con el entorno creado}

En el cristianismo, Dios es amor sobreabundante que crea. El hombre fue creado por amor y para el amor, para celebrar su existencia y ser grato a su creador, conociéndolo, amándolo y sirviéndolo. Desde esta cosmovisión religiosa, un hombre que, simultáneamente ama a Dios, ama al otro, reconoce y cuida su entorno, se ama a sí mismo practicando el autocuidado antes referido y reconociendo la creación como acto amoroso y primordial en su vida.

Dios es amor que se manifiesta en todo lo bueno que rodea al ser humano, expresándose, de modo especial, en actos bondadosos y generosos que celebran el amor. En el escenario en el que el celebrante hombre enaltece a su Dios y le ama, el acto se denomina devoción, amor del alma que también resiste la revisión racional y que la confirma en su amor a Dios. Tomás de Aquino (1994), usa el concepto de religión -definida como la virtud por la cual se le tributa a Dios el culto que le es debido- y de devoción, esta última entendida por el Aquinate como un acto especial de la voluntad que consiste en hacer con prontitud lo que pertenece al servicio de Dios.

Amar la casa en que habita es actitud propia del hombre que ama a los semejantes y a todo aquello que le resulta provechoso en vistas a su subsistencia. El hombre interactúa, es creatura como sus semejantes y, mediante sus sentidos, descubre el cosmos como orden (Brague, 2008). El hombre no niega el entorno ni la naturaleza creada. Su obrar permanente hace que establezca una relación con los demás y con las cosas; el hombre es invitado a amar el entorno que, al serle provechoso, es "amable", o sea, digno de ser amado. 
Cuando el entorno le prodiga beneficios al hombre, sin duda se convierte en amado. La dinámica resulta en un hombre que ama todo aquello con lo que se relaciona y, al mismo tiempo, es amado por Dios a través del mundo creado en el que expresa sus perfecciones.

\section{Conclusión}

En la posmodernidad se relegó el amor meramente a la sensación y, por ende, a la irracionalidad. No ahondar en su concepto es privarse de conocer muchas de las cualidades con las que el amor hace que el hombre pueda vivenciar un verdadero gozo, una alegría sublime, más fuerte, incluso, que las sensaciones meramente físicas y que el frenesí del emotivismo contemporáneo.

El amor está en todo y esta es una verdad que se ha pregonado mucho. No obstante, el hombre contemporáneo se niega a salir en su búsqueda. Constatarlo es aprehenderlo, conocer de qué se trata, ponerlo en práctica, hacer de él un modo permanente en los propios actos y, de paso, congraciarse con sus cualidades estimulantes, satisfactorias y fructíferas. El amor está concebido para el bienestar del hombre y se realiza plenamente viviendo el buen amor, siendo buen amante. Es primordial el amor porque es el sentimiento de sentimientos y, a su vez, el modo de modos. Desde temprana edad, el amor se recibe con el modo materno que prodiga cuidado, un modo en el que el amor se hace práctico. En adelante, el amor se testimonia e invita a practicarse, a vivirse, a materializarse ¿̨Por qué los hombres se distraen en el mero goce, en la sensación y no en la trascendencia del amor? El amor es el modo primordial de relación, requiere de la inteligencia y de la conciencia, sin las cuales puede ser nocivo. Lo que se hace con amor y conciencia es promisorio para los amantes y el entorno. El amor viene bien entre hombres y mujeres, así como en las relaciones humanas, los negocios, la educación y el servicio.

Lo hecho en modo amor es asertivo, da rédito, se hace con detalle y reverencia. La minuciosidad del acto amoroso se expresa, sencillamente, en la sonrisa del tejedor y en su paciencia alegre, que surgen de la certeza de que su manto será provechoso y útil al depositario. El amor es solo uno, expresado por y para cada cual en distintos escenarios: la amistad, la inquietud de los que se quieren eternizar en pareja, el padre que es magnánimo en su trabajo por amor a sus hijos, el sacerdote que renuncia a la vida de familia por los fieles. El amor es la buena intención del hombre materializada en la relación que, como dijo San Agustín de la verdad, subsistirá, aunque se aniquile el mundo, porque Dios mismo es relación de amor, el modo primordial de Dios es amor.

\section{Referencias}

Abrams, M.H. (1992). El Romanticismo: Tradición y revolución. Madrid: Visor.

Bauman, Z. (2005). Amor líquido. Acerca de la fragilidad de los vínculos humanos. México: Fondo de Cultura Económica. Brague, R. (2008). La sabiduría del mundo. Historia de la experiencia humana del universo. Madrid: Encuentro.

Burgos, J.M. (2009). Antropología. Una guía para la existencia. Madrid: Palabra. 
Burgos, J.M. (2012) Introducción al Personalismo. Madrid: Palabra.

Catecismo de la Iglesia Católica. (2004). Santiago de Chile: San Pablo.

Cruz Cruz, J. (1999). El éxtasis de la intimidad. Ontología del amor humano en Tomás de Aquino. Madrid: RIALP.

De Aquino, T. (1994). Suma de Teología IV. Parte II-II(b). Madrid: Biblioteca de Autores Cristianos.

De Hipona, S.A. (1958). Obras de San Agustín. Edición Bilingüe Tomo XVII. La Ciudad de Dios. Madrid: Biblioteca de Autores Cristianos.

Domingo Moratalla, A. (2013). El arte de cuidar. Atender, dialogar y responder. Madrid: RIALP.

Esparza, M. (2013). Amor y autoestima. Madrid: RIALP.

Ferrater Mora, J. (2004) Diccionario de Filosofía. Barcelona: Ariel.

Figari, L.F. (2004). Un mundo en cambio. Lima: Vida y Espiritualidad.

Foucault, M. (2011). Hermenéutica del sujeto. México: Fondo de Cultura Económica.

Garcés Giraldo, L.F \& Giraldo Zuluaga, C. (2013). El cuidado de sí y de los otros en Foucault, principio orientador para la construcción de una bioética del cuidado. Discusiones filosóficas (22): 187-201.

García Casas, P. (2018). Amor es nombre de persona en Karol Wojtyta. Barcelona: Herder.

Gómez Rodas, C.A. (2013). Sensualidad y erotismo. Una mirada desde Georges Bataille y Nicolás Gómez Dávila. Quid (20): 55-62.

Gómez Rodas, C.A. (2019). Realismo ético y conversión del deseo. Aportes éticos y pedagógicos a partir de San Agustín de Hipona. En C. Lértora y S. Violante (Eds.), Temas y problemas de filosofía medieval (pp. 11-18). Buenos Aires: Red Latinoamericana de Filosofía Medieval.

Gómez Rodas, C.A., Castellanos Muñoz, A.G. \& Amaya de Armar, T.R. (2020). La Gran Moral. MacIntyre y el carácter integrador de la filosofía perenne. Prometeica (20): 80-92.

Hadot, P. (2006). Ejercicios espirituales y filosofia antigua. Madrid: Siruela.

Hahn, K. (2001). El amor que da vida. El maravilloso plan de Dios para el matrimonio. Madrid: RIALP.

Hahn, S. (2009). Lo primero es el amor. Descubre tu familia en la Iglesia y en la Trinidad. Madrid: RIALP.

Heidegger, M. (2002). El ser y el tiempo. México: Fondo de Cultura Económica.

Lewis, C.L. (2014). La abolición del hombre. Buenos Aires: Vórtice.

López, S.G. (2020). Amar para participar en comunidad: una propuesta desde la psicología comunitaria y la teoría de la participación wojtyliana. QUIÉN. Revista De filosofía personalista, 11: 83-101.

López Quintás, A. (2013). El descubrimiento del amor auténtico. Claves para orientar la afectividad. Madrid: Biblioteca de Autores Cristianos.

Nácar Fuster, E. \& Colunga Cueto, A. [Trads.] (1969). Sagrada Biblia. Versión directa de las lenguas originales. Madrid: Biblioteca de Autores Cristianos.

Pabón de Urbina, J. M. (2009). Diccionario Manual Griego. Griego Clásico-Español. Madrid: Vox.

Pieper, J. (2006). Una teoría de la fiesta. Madrid: RIALP. 


\section{Sergio Molina Pérez}

Pieper, J. (2017). Las Virtudes Fundamentales. Madrid: RIALP.

Platón. (1992). Diálogos VII. Dudosos, Apócrifos, Cartas. Madrid: Gredos.

Polaino, A. (2000). Madurez personal y amor conyugal. Factores psicológicos y psicopatológicos. Madrid: RIALP.

Quiles, M.J. \& Espada, P.J. (2010). Educar en la autoestima. Propuestas para la escuela y el tiempo libre. Madrid: CCS.

Rojas, E. (2004). Los lenguajes del deseo. Claves para orientarse en el laberinto de las pasiones. Buenos Aires: Temas de Hoy.

Seifert, J. (2018). Amor verdadero. Madrid: Encuentro.

Yepes Stork, R. \& Aranguren Echevarría, J. (2003). Fundamentos de Antropología. Un ideal de la excelencia humana. Madrid: RIALP.

Zubiri, X. (1980) Naturaleza, Historia, Dios. Madrid: Alianza. 